\title{
O Iluminismo e a expulsão dos jesuítas do Império Português; as reformas pombalinas e o plano dos estudos menores
}

\author{
Enlightenment and the expulsion of the Jesuits from the \\ Portuguese Empire; Pombal's reforms and the plans for "minor \\ studies"
}

\section{Teresa da Fonseca Rosa*}

\begin{abstract}
Resumo
Com a publicação da sentença da expulsão da Companhia de Jesus em 12 de Janeiro de 1759 e com o confisco de todos os seus bens, o Marquês de Pombal viu-se confrontado com a falta de estabelecimentos de ensino que pudessem acolher os estudantes dos Colégios Jesuítas entretanto fechados. Assim pela publicação a 28 de Junho do mesmo ano de uma reforma geral, Alvará que extingue em definitivo todas as escolas jesuítas, foram criadas a partir de então aulas régias gratuitas de gramática latina, de grego e de retórica. Esta mesma Lei impôs uma centralização régia deste tipo de ensino com a criação do cargo de Diretor-geral dos Estudos. Esta reforma pombalina dos estudos foi realizada em duas fases distintas, a primeira, que teve início em 1759 e se prolongou até 1771 , foca-se essencialmente em resolver o problema deixado pelo fecho dos Colégios Jesuítas. A segunda fase, que se inicia em 1771 com a Real Mesa Censória, incidiu na reforma das primeiras letras, do ensino médio (estudos menores) e da Universidade de Coimbra. No presente estudo realizamos uma análise sobre os Estudos Menores no período que corresponde ao primeiro quadro do Projeto Atlas-Repertório dos Municípios (1770-1801), reconstituindo a rede escolar.
\end{abstract}

Palavras-chave: Jesuítas. Reformas pombalinas e marianas. Estudos menores. Congregações religiosas. Rede escolar.

\begin{abstract}
Upon the publication of the sentence for the expulsion of the Society of Jesus on January $12^{\text {th }}, 1759$, and the confiscation of all their goods, Marquis
\end{abstract}

\footnotetext{
Doutora em História da Educação, Bolseira/Investigadora da FCT (Fundação para a Ciência e Tecnologia do Ministério da Educação). Pós-doutoranda em História da Educação, no Instituto de Educação da Universidade de Lisboa e Investigadora/Colaboradora da UIDEF (Unidade de Investigação e Desenvolvimento para a Educação e Formação), do Instituto de Educação da Universidade de Lisboa. E-mail: teresadafons@gmail.com
} 
of Pombal was faced with a lack of schools to accommodate students from the Jesuit Colleges closed. The publication on June $28^{\text {th }}$ of a document, in the same year, brought a total reform, extinguishing definitively all Jesuit schools an established the creation of royal free grammar lessons of Latin, Greek and Rhetoric. This same law imposed a royal centralization of this type of education with the creation of the post of Director General of Studies. This Pombal Reform of the education was conducted in two distinct phases, the first one started in 1759 until 1771 and focused primarily on solving the problem left by the closure of Jesuit Colleges. The second phase, which began in 1771 with the Royal Censorship Bureau, focused on the reform of primary education, of middle school (under study) and of University of Coimbra. The current study performs an analysis on the Minor Studies in the period corresponding to the first frame of the Atlas Project - Directory of Municipalities in Education and Culture in Portugal (1770-1801).

Keywords: Jesuits. Pombal and Marianas reforms. Minor studies. Religious congregations. School network.

\section{Antecedentes Históricos}

\section{O estabelecimento da Companhia de Jesus em Portugal e os Colégios criados até meados do século XVIII}

Portugal foi o primeiro reino da Cristandade a solicitar os serviços da Companhia de Jesus, pois que tal solicitação data do ano anterior à sua instituição oficial. A procura de religiosos bem preparados, para realizar o programa de doutrinação cristã, que coexistia com o projeto econômico da expansão portuguesa, levou D. João III a acolher em Portugal, logo no ano de 1540, a nova Ordem inaciana, recém-fundada a qual rapidamente ganhou estima por parte do monarca.

A sugestão foi dada por um dos estudantes bolsistas enviados por D. João III à Universidade de Paris, Diogo de Gouveia, “O Velho", que mais tarde viria a desempenhar, as funções de Principal no Colégio de Santa Bárbara e de Reitor dessa mesma Universidade.

Também em Paris, no Colégio de Santa Bárbara, se instruíram Inácio de Loyola e os seus companheiros fundadores da Companhia de Jesus. Refere Isabel Rosendo, que "os Inacianos pautavam-se pela renovação cultural e 
pelos métodos do humanismo". ${ }^{1}$ A feição nova da Companhia de Jesus, tal como sugere Silva Dias,

chocou os intelectuais da escola monástica tanto em Portugal como no estrangeiro (...). A supressão do coro, a simplificação do ofício divino e do cerimonial litúrgico, o aligeiramento das penitências corporais, patenteiam o desejo não de recluir o mundo nos conventos, mas de levar os conventos para o meio do mundo. (...) E a surpresa acentua-se com a simpatia de alguns jesuítas pela espiritualidade de sabor iluminado. ${ }^{2}$

Assim se pode compreender as reações contraditórias, que provocaram quando se instalaram nos seus primeiros Colégios em Portugal.

De facto, D. João III não só lhes concedeu importantes meios materiais e financiamento económico, assim como, a proteção política e recomendação diplomática, abrindo-lhes as "portas ao mundo", através do vasto império ultramarino português.

A ação catequizadora da Companhia de Jesus estava a transformar-se num forte apelo ao revigoramento espiritual da população, quer pela pregação quer por meio da confissão, de acordo com uma tendência geral do catolicismo tridentino, donde resultou um aumento da devoção das camadas jovens. Rapidamente os membros do grupo fundador desta nova Ordem ganharam a percepção de que a aposta na educação seria um grande meio para transformar a velha sociedade cristã, incutindo-lhes uma nova consciência. Pelo ensino, a Companhia acreditava transformar a sociedade à luz do seu ideário "reformista católico" e, ao mesmo tempo, assegurar a sua afirmação enquanto Ordem.

Desta forma, o êxito da atuação dos Jesuítas, nos locais onde se iam instalando, fê-los considerar a conveniência de eles próprios fundarem as suas escolas públicas, onde fosse permitida a frequência de estudantes leigos, nas quais eles, Jesuítas, fossem os mestres. Prática que veio a constituir uma das principais marcas da identidade inaciana. ${ }^{3}$

Ao mesmo tempo, este investimento na educação permitiu ainda recrutar e formar, qualificadamente, missionários e professores das novas gerações. Porém, a obra educativa dos Jesuítas situava-se especialmente nos

\footnotetext{
${ }^{1}$ ROSENDO, Ana Isabel Rodrigues da Silva. Inácio Monteiro e o Ensino da Matemática em Portugal no século XVIII. Braga: Universidade do Minho, 1996, p. 19.

${ }^{2}$ DIAS, José Sebastião da Silva. As Correntes de Sentimento Religioso em Portugal (séculos XVI a XVIII). Tomo I. Coimbra: Universidade de Coimbra, 1960, p. 169-17.

${ }^{3}$ ROSA, Teresa Rodrigues da Fonseca. História da Universidade Teológica de Évora. Lisboa: Instituto da Educação da Universidade de Lisboa, 2013, p. 20.
} 
níveis de ensino médio e superior, não sendo o ensino elementar considerado como parte indispensável do seu programa educativo. Ensinar a ler e a escrever seria também considerado obra de caridade; contudo, tal só se verificaria se os inacianos tivessem gente suficiente que pudesse acudir a tudo. Mas por falta de pessoal, "ordinariamente não se ensinará". ${ }^{4}$ A educação das massas populares fazia-se essencialmente pela pregação e pela catequese, como afirma Áurea Adão. ${ }^{5}$ Embora os Jesuítas se mostrassem reticentes, no que respeita ao ensino das primeiras letras, existem notícias de "mestres de ler e escrever" em muitos colégios dirigidos por eles. ${ }^{6}$ Tais mestres ensinavam a "ler escrever e contar", a doutrina cristã e o canto, ${ }^{7}$ e tanto poderiam ser membros da Companhia, como outros eclesiásticos propostos para o efeito.

Esta nova atividade foi-se desenvolvendo lentamente, desde os anos quarenta do séc. XVI até à sua extinção em 1759. O número de Colégios aumentou invulgarmente e veio a cobrir todo o território nacional. Craveiro da Silva diz mesmo: "Comparativamente à população, cremos que nunca até hoje, houve centros de ensino em Portugal tão frequentados por alunos [...] como o dos Jesuítas dos séc. XVI ao séc. XVIII". ${ }^{8}$

O percurso na criação dos seus Colégios, privilegiou uma implementação essencialmente urbana, nos aglomerados mais populosos das principais cidades. Esta dimensão de urbanidade, que caracterizou de forma distinta a atividade dos Jesuítas, não deixou de revelar um enlace estratégico que esta nova Ordem assumiu, para responder aos desafios da modernidade. Realcemos ainda, que a Companhia de Jesus lançou, em Portugal, as bases para a criação de uma autêntica rede de Colégios de Norte a Sul do País, não deixando de se estender às Ilhas Atlânticas, aquela que alguns autores consideram como tendo sido a precursora da contemporânea "rede nacional de ensino portuguesa".

Com efeito, logo no ano de 1542, foi fundada em Lisboa a primeira casa que os Jesuítas possuíram como própria no mundo: a comunidade do

\footnotetext{
${ }^{4}$ GOMES, Joaquim Ferreira. O Ratio Studiorum da Companhia de Jesus. Revista Portuguesa de Pedagogia, Ano XXV, N. 2, 1991, p. 139.

${ }^{5}$ ADÃO, Áurea. O Estado Absoluto e o Ensino das Primeiras Letras. Lisboa: Serviços de Educação, Fundação Calouste Gulbenkian, 1997, p. 20.

${ }^{6}$ ROSA, Teresa Rodrigues da Fonseca. 0 Colégio da Ascensão de Angra do Heroísmo: Uma Análise Pedagógica da Companhia de Jesus. Um Contributo para a História da Educação em Portugal. Angra do Heroísmo: dissertação de Doutoramento em História da Educação, apresentada à Universidade dos Açores, 2005, p. 90 (texto policopiado).

${ }^{7}$ ADÃO, op. cit., p. 23.

${ }^{8}$ SILVA, Lúcio Craveiro da. Os Jesuítas e o Ensino Secundário. Brotéria, N.31, 1940, p. 482.
} 
Mosteiro de Santo Antão-o-Velho. No mesmo ano, foi instituída em Coimbra, com o nome de Colégio de Jesus, a primeira casa para a formação de jovens Jesuítas. Em Évora, os religiosos da Companhia estabelecem-se, no ano de 1551. Nesse ano, começou de facto a funcionar o Colégio do Espírito Santo, mas apenas como casa de formação para Jesuítas e sacerdotes.

A sua primeira escola pública, fundada em Portugal, foi o Colégio de Santo Antão, em Lisboa, nos princípios de 1553, no mesmo ano o Colégio do Espírito Santo de Évora, que foi elevado a Universidade em 1559. Em Coimbra, o Colégio das Artes, mantendo a exclusividade do ensino das Artes (Gramática, Humanidades, Retórica e Filosofia), viria a ser entregue por D. João III aos Jesuítas, depois de um processo atribulado, logo em 1555, libertando-o da autoridade universitária e mantendo a sua finalidade: formar bacharéis, licenciados e mestres em Artes, e ministrar o ensino preparatório para o ingresso na Universidade. Notemos que, ao longo destes séculos e até à sua expulsão de Portugal, em 1759, nem sempre foi pacífica a relação entre a Universidade de Coimbra e o Colégio das Artes. Este fazia parte da Universidade, mas não estava sob a jurisdição ${ }^{9}$ da mesma. Os mestres e alunos do Colégio tinham as mesmas prerrogativas que os lentes e estudantes das "escolas maiores", sendo inclusivamente autónomo na organização dos exames dos bacharéis e licenciados. Contudo, não tinha dotação financeira própria. ${ }^{10}$ Outras fundações se seguiram.

No século XVI foram fundados: a Casa Professa de São Roque em 1553; o Colégio de São Paulo fundado em 1560, em Braga; o Colégio de São Lourenço fundado em 1560, no Porto; o Colégio do Santo Nome de Jesus fundado em 1561, em Bragança; o Colégio de São Manços dos Porcionistas fundado em 1563, em Évora; o Real Colégio São João Evangelista fundado em 1570, no Funchal; o Real Colégio da Ascensão de Cristo fundado em 1570, em Angra do Heroísmo; o Colégio da Purificação de Nossa Senhora fundado 1576, em Évora; o Colégio da Madre de Deus fundado em 1583, em Évora; o Colégio de São Patrício fundado em 1590, em Lisboa; a Residência de São Miguel fundada em 1591, em Ponta Delgada; o Seminário do Monte Olivete, em Lisboa em 1597; o Colégio de São Tiago fundado em 1599, em Faro. ${ }^{11}$

No século XVII foram fundados: a Casa Professa de Vila Viçosa em 1601; o Colégio de S. Sebastião fundado em 1605, em Portalegre; o Noviciado

\footnotetext{
${ }^{9}$ A.R.S.I., Lus. № 60, Epistolae Lusitaniae, (1556-1560), fls. 46v.- 47.

${ }^{10}$ CARVALHO, Rómulo de. História do Ensino em Portugal. Lisboa: Serviço de Educação, Fundação Calouste Gulbenkian, 2011, p. 318-325.
}

${ }^{11}$ ROSA, O Colégio da Ascensão, op. cit., p. 92. 
da Cotovia em Lisboa em 1619; o Colégio de Todos os Santos, em Ponta Delgada e o Colégio de Nossa Senhora da Conceição, em Santarém, foram fundados em 1621; o Colégio de São Tiago fundado em 1644, em Elvas; o Colégio de São Francisco Xavier fundado em 1652, no Faial; o Colégio de São Francisco Xavier fundado em 1655, em Setúbal; o Colégio São Francisco Xavier fundado em 1660, em Portimão; a Escola da vila de Pernes ${ }^{12}$ fundada em 1662 por uma fidalga, D. Ana da Silva, que deixou uma renda para se abrir uma escola de latim; o Colégio São Francisco Xavier fundado em 1670, em Beja; o Colégio São Francisco Xavier fundado em 1679, em Lisboa; a Residência da Santíssima Trindade fundada em 1693, em Gouveia.

No século XVIII foram fundados: o Colégio e Noviciado de São Francisco Xavier, em Arroios - Lisboa, no ano de 1705; a Escola de Nossa Senhora da Lapa, em Lisboa, em 1714; o Seminário dos Santos Réis, em Vila Viçosa e o Seminário e Noviciado das Missões, em Lisboa ambos em 1735; e o Colégio de Santíssima Trindade em Gouveia, em 1739. ${ }^{13}$

Em Portugal, na primeira metade do século XVIII, a cultura e o ensino continuaram sob o domínio quase completo da Ordem inaciana. No entanto, encontramos igualmente, outras Ordens religiosas, embora com menos preponderância, instaladas no País e dedicadas também ao ensino, tais como a Ordem dos Clérigos de São Caetano, estabelecida em 1648, e a Congregação do Oratório de São Felipe de Néri. Esta Congregação, fundada em Roma, em 1550, e introduzida em Portugal no reinado de D. João IV pelos Padres Bartolomeu de Quental e Francisco Gomes, revelou-se uma instituição preponderante e charneira na edificação de uma nova matriz cultural em Portugal.

Embora quase tão antiga como a Companhia de Jesus, patenteou-se sempre mais permeável às orientações modernas, mais aberta às tendências culturais do século, preocupando-se sobretudo com o ensino das ciências experimentais e da língua portuguesa. Vieram pois a ter um papel activo nas reformas pedagógicas empreendidas por Carvalho e Melo.

Ainda antes das Reformas Pombalinas, a Congregação do Oratório chegou a ter, em Portugal, casas, nas quais também era ministrado o ensino secundário de humanidades e, em várias delas, o de filosofia e de teologia. Destas destacam-se: a Casa de Nossa Senhora das Necessidades, em Lisboa, fundada no ano de 1645; a Casa do Espírito Santo, fundada em Lisboa, no

\footnotetext{
${ }^{12}$ Residência anexa ao Colégio de Santarém (Residência de Pernes), com obrigação de uma classe de gramática latina e outra de ler e escrever. In: ADÃo, op.cit., 1997, p. 21. Cf. A.N.T.T., Cartório Jesuítico, maço 72, doc. 10.

${ }^{13}$ ROSA, O Colégio da Ascensão, op. cit., p. 92.
} 
ano de 1659 e que veio a ser destruída pelo terramoto de 1755; a Casa em Freixo de Espada à Cinta; em 1685, na cidade do Porto; em 1689, em Viseu; em 1690, em Braga; em Estremoz, em 1701, e em Monção, no ano de 1749. Refere Eugénio dos Santos, que esta Congregação não "nasceu essencialmente pedagógica" 14 como a sua congénere Ordem Inaciana, mais de um século antes. No entanto, no final do reinado de D. João V esta situação foi alterada pelo decreto Régio de 9 de Fevereiro de 1745. 0 monarca doou à Congregação o hospício das Necessidades, em Lisboa, dotando-o com doze mil cruzados anuais e atribuindo-lhe o encargo de manter "perpetuamente quatro classes de ensino: doutrina cristã, ler, escrever, e contar; gramática e retórica; teologia moral, filosofia, podendo também no futuro, preleccionar teologia especulativa e outra qualquer ciência ou faculdade", ${ }^{15}$ ficando ainda a cargo desta uma livraria que conservava trinta mil volumes. ${ }^{16}$

Durante os finais do século XVII e toda a primeira parte do século XVIII, o Oratório contribuiu decisivamente para a afirmação de um novo paradigma de clérigo, em sintonia com os novos rumos da ciência. Isto acentuou cada vez mais a relevância da sua ação pedagógica, podendo salientar-se a atenção dada por D. João V quando estendeu aos alunos da Congregação o privilégio de entrada directa na Universidade, até então exclusivo dos alunos Jesuítas do Colégio das Artes. ${ }^{17}$

Foi, pois, no período joanino, que a Congregação do Oratório alcançou o auge do seu prestígio, alargando até geograficamente, com a autorização de abertura de um hospício, para apoio cultural em Monção, no Norte de Portugal. Este prestígio, que se manteve com algum vigor até ao início do século XIX, viu passar pelos bancos das suas aulas alguns nomes de destaque como Luís António Verney, D. Manuel do Cenáculo Villas Boas, e mesmo Alexandre Herculano.

Na primeira metade do século XVIII, a cultura e o ensino continuou sob o domínio quase completo da Companhia de Jesus. A preponderância no ensino, adquirida durante os séculos XVI e XVII, acabou por entrar em conflito com um conjunto de homens que, através de perspectivas culturais diferentes, lhes criticaram os métodos pedagógicos e procuraram a mudança,

\footnotetext{
${ }^{14}$ SANTOS, Eugénio dos. O Oratório no Norte de Portugal. Contribuição para o estudo da História Religiosa e Social. Porto: Edições INIC, 1982, p. 285.

${ }^{15}$ ADÃO, op. cit., p.26.

${ }^{16}$ SANTOS, op. cit., p.51.

${ }^{17}$ SANTOS, Eugénio de. Oratorianos. In: Dicionário Histórico das Ordens e Instituições Afins em Portugal. Lisboa: Gradiva, 2010, p. 231-240.
} 
quer das matérias a ensinar quer da mentalidade da "classe" dominante. Importa sublinhar que a Companhia de Jesus manteve-se contrária à introdução de alterações profundas nos seus métodos pedagógicos e nas matérias lecionadas. De uma maneira geral, o ensino continuou ligado ao conceito humanista, tendo por base a língua latina.

Em Portugal, os Jesuítas não desconheciam nem eram alheios às novidades. A sua atitude face a esses novos ideais e tendência era, em meados do século XVIII, "a de simpatizantes inteligentes e de activos colaboradores". ${ }^{18}$ Esta opinião é partilhada também, por Domingos Maurício dos Santos. Para ele o cultivo das ciências entre os inacianos estava em franco progresso desde o início do mesmo século, e este desenvolvimento, que também se refletiu na Filosofia, é anterior à publicação do Verdadeiro Método de Estudar e à influência exercida pelos Oratorianos. ${ }^{19}$ Não obstante, estas posições não foram partilhadas por diversos autores da corrente contrária, que defendiam que os Jesuítas foram os principais responsáveis pelo atraso cultural e científico da época.

Não podemos esquecer, que os Jesuítas estavam sujeitos a uma disciplina e uma organização muito rígida e severa, e por isso foi muito difícil, para os que desejavam que a Ordem se reformasse e acompanhasse os novos desafios, lutar contra uma "máquina gigantesca", com uma tradição fortíssima. Apesar disso, se por um lado a Companhia de Jesus não alterou profundamente a sua "filosofia pedagógica" nos séculos XVII e XVIII, isso não significa que

não estivessem a par das mudanças filosóficas e científicas que iam ocorrendo na Europa e que não houvesse inacianos muito interessados e conhecedores dessas transformações, gente de altíssima craveira intelectual que não tivesse tomado consciência do real valor das suas novas propostas e também dos seus erros e perigos para a ortodoxia(....). ${ }^{20}$

Com efeito, alguns Jesuítas em Portugal revelaram entusiasmo, abertura, e apelaram para a urgência de uma renovação em alguns campos; outros resistiram a essa viragem.

Por outro lado, na última década do reinado de D. João V, assiste-se a uma acentuada perda de poder e de preponderância da Companhia de Jesus

\footnotetext{
${ }^{18}$ GOMES, João Pereira. Perante Novos Sistemas e Novas Descobertas. Brotéria, 39, 1944, p. 378.

${ }^{19}$ SANTOS, Domingos Maurício Gomes dos. Para a História do Cartesianismo entre os Jesuítas Portugueses do século XVIII. Revista Portuguesa de Filosofia, Tomo I, fasc.1, Janeiro-Março, Lisboa, 1945, p. 27-44.

${ }^{20}$ MONTEIRO, Miguel Corrêa. O Padre Inácio Monteiro (1724-1812), um Jesuíta Português na Dispersão: Contribuição para a história da Companhia de Jesus durante a época das "Luzes". Lisboa: Universidade de Lisboa, 2000, p. 85.
} 
junto do monarca, o que já se vinha a verificar desde o início do seu longo reinado, em detrimento da Congregação do Oratório, a quem manifestou o sua preferência e favoreceu largamente.

Os Oratorianos começaram a disputar com êxito, a visibilidade aos Jesuítas nas esferas religiosas, socio-estatais e culturais. Mas mais importante neste período, será o acentuar das controvérsias em torno da pedagogia Jesuíta, no quadro teórico-epistemológico e científico que suportava, dirigidas por autores de filiação intelectual iluminista.

\section{Política Educativa e Reforma Pombalina dos Estudos}

Durante o reinado de D. José I, definiram-se, como é sabido, várias linhas de orientação nomeadamente políticas, econômicas e culturais. 0 monarca viu-se obrigado a combater estruturas governativas e administrativas seculares, cuja natureza em nada ajudava o Estado a responder com eficácia ao incremento de toda uma atividade comercial, potenciadora de riqueza e de modernização cultural. A conduta das classes sociais tradicionais, marcada por divergências, fazia-as enredadas numa teia à sombra do Estado.

Por outro lado, longo foi o período em que a Igreja dispôs do ensino, segundo os seus princípios e as suas conveniências, mas à medida que foi sendo divulgada a influência do Iluminismo, a sua preponderância sobre o ensino foi enfraquecendo. O Iluminismo que se caracterizou essencialmente pela preocupação de limitar os poderes da Igreja em áreas de interesse social, como as do Ensino, a Assistência e a Justiça, fez com que surgisse, também em Portugal, uma mentalidade acerca da Educação.

O reinado de D. José I marcou este ponto de viragem político, mas também cultural e social. O monarca concedeu plenos poderes a Sebastião José de Carvalho e Melo, a quem elevou aos títulos de Conde de Oeiras (1759) e Marquês de Pombal (1770). Sebastião José era também um "estrangeirado", tinha vivido alguns anos fora do país, desempenhara funções diplomáticas em Londres e Viena, o que terá contribuído para lhe alargar os horizontes culturais e ganhar confiança numa administração pública disciplinada.

Convidado para integrar o Governo como Secretário de Estado dos Negócios Estrangeiros, acabou por ganhar a confiança do Rei, vindo a ser nomeado Secretário do Estado e Ministro do Reino. Toda a ação do Primeiro-Ministro visou o fortalecimento do poder real, afastando quantos se opunham aos seus interesses, e ao mesmo tempo tentando recuperar o atraso que o país levava, em muitos sectores, em relação a outros países da Europa. Para reforçar o Estado, Pombal precisou de diminuir o poder de dois 
adversários poderosos: alguns grandes fidalgos, que transgrediam os seus poderes em detrimento dos interesses do Estado; e a Companhia de Jesus, que tinha uma profunda influência no país e na colónia Brasil. Mercê da sua acção no ensino, na missionação e na corte, os Jesuítas foram assim lentamente envolvidos nos "jogos" de poder e entraram em choque com o despotismo esclarecido. ${ }^{21}$

O atentado de 1758 contra o rei D. José I, forneceu ao Marquês de Pombal o pretexto para destituir os "poderosos" do reino, nomeadamente os Aveiros e os Távoras. Os Jesuítas também não foram poupados, tendo sido acusados de envolvimento no mesmo. De forma discreta, foi promovida pelo Ministro Carvalho e Melo, através da Junta da Inconfidência, uma demorada averiguação das responsabilidades.

O Tribunal da Inconfidência, presidido por Pombal, conduziu um severo interrogatório, onde envolveu: um grupo de Jesuítas como conspiradores e autores morais de tentativa de regicídio, sendo este crime qualificado como "lesa-majestade de primeira cabeça de alta traição, rebelião e parricídio"; em associação com os nobres condenados, e também a Companhia de Jesus em Portugal.

Como referido anteriormente, até então em Portugal, o ensino era maioritariamente ministrado por Jesuítas. O ensino era também ministrado em algumas escolas dos Oratorianos, e em escolas geralmente pequenas, a cargo das Câmaras, da Igreja e de Congregações religiosas, nas localidades onde tal ensino não chegava. Nelas eram lecionadas especialmente o latim e as primeiras letras. Podemos considerar, ainda, a existência de professores particulares.

À expulsão dos Jesuítas ordenada em 1759, em sentença publicada a 12 de Janeiro, seguiu-se a proibição de ensinar em todos os domínios portugueses, decretada por Alvará Régio de 28 de Junho do mesmo ano. Além de privar os Jesuítas do ensino, este Alvará Régio continha as bases de uma "nova" metodologia para as Escolas Menores, criava o cargo de Diretor-geral dos Estudos, assim como, instituía o Colégio dos Nobres em Lisboa.

Pouco depois, a 3 de Setembro do mesmo ano, os Jesuítas eram desnaturalizados, presos ou expulsos do Reino, de modo que foi praticamente impossível a reconstituição dos seus Colégios. Dada a extinção repentina dos Colégios, tal como sublinha António Leite, impunha-se

21 MONTEIRO, op. cit., p. 991. 
que se providenciasse para que os numerosos alunos que frequentavam aqueles estabelecimentos de ensino pudessem continuar os estudos. Nos primeiros tempos, Pombal favoreceu o desenvolvimento dos Colégios da Congregação do Oratório, cujos livros escolares foram em grande parte aprovados para os novos estudos. Mas, mais tarde, nos anos de 1768 e 1769 , também os Oratorianos foram proibidos de ensinar, sob o pretexto, de «inconfidências» e de ensinarem doutrinas perniciosas à mocidade e de adesão ao bispo de Coimbra, D. Frei Miguel da Anunciação (...). ${ }^{22}$

\section{Os Estudos Menores}

Durante os primeiros nove anos de governação do Marquês de Pombal, os Jesuítas mantiveram a direção em quase todo o ensino preparatório, que dava acesso aos Estudos Superiores. Tal como sublinha Áurea Adão,

com a publicação da sentença da expulsão dos Jesuítas de todo o território português, em 12 de Janeiro de 1759, acusados do crime lesa-majestade, e com o confisco dos respectivos bens, o Marques de Pombal viu-se confrontado com a falta de estabelecimentos de ensino que pudessem acolher os estudantes dos colégios jesuítas, entretanto fechados. ${ }^{23}$

Para suprir esta lacuna, D. José I publicou a 28 de Junho de 1759 uma "geral reforma". Este Alvará extingue, em definitivo, todas as escolas jesuítas, ficando os próprios proibidos, em absoluto, de todos os estudos. A partir de então, foram criadas aulas régias gratuitas de Gramática Latina, de Grego e de Retórica. Esta mesma lei impôs, pela primeira vez, uma centralização régia deste tipo de ensino com a criação do cargo de Director Geral dos Estudos. Este mesmo diretor tinha como funções fazer cumprir as disposições do diploma, ficando a ele subordinados todos os professores régios destas mesmas disciplinas. Esta diretoria manteve-se em funções durante aproximadamente onze anos (14-08-1759 a 5-12-1770), tal como refere António Leite. ${ }^{24}$

O mesmo diploma de 28 de Junho criou, em cada bairro de Lisboa, uma classe de gramática latina, e uma ou duas, em cada uma das vilas das Províncias. Determinou ainda, que seriam estabelecidas cadeiras de retórica: quatro em Lisboa, duas em Coimbra, duas em Évora, duas no Porto, e uma em cada uma das cidades e vilas que eram cabeça de comarca. Dos Estudos Menores fazia também parte a cadeira de Filosofia, tendo sido nomeados

\footnotetext{
${ }^{22}$ LEITE, António. Pombal e o Ensino Secundário. In: Como Interpretar Pombal?. Lisboa: Edições Brotéria, 1983, p. 173-174.

${ }^{23}$ ADÃo, op. cit., p. 44.

${ }^{24}$ LEITE, op. cit., p. 174.
} 
quatro professores: um para Lisboa, um para Coimbra, um para Évora e um último para o Porto. ${ }^{25}$ Trata-se do primeiro esboço de um ensino oficial cuja imagem de marca será a laicização do professorado e a adaptação dos métodos e conteúdos propostos por Luís António Verney, lançando as bases de uma nova metodologia para as Escolas ditas Menores.

A Lei pombalina, tem como primeira preocupação privar oficialmente os Jesuítas de desempenharem quaisquer funções educativas no País, e acabar com dois séculos de atividade pedagógica em Portugal. Importa destacar ainda que a primeira medida legislativa referente ao ensino do Reino fora tomada por Pombal a 19 de Abril de 1759, quando aprovou os Estatutos de uma Aula do Comércio, sediada em Lisboa. Requerida pela própria classe mercantil e gerida pela Junta do Comércio, tinha em vista a preparação de negociantes portugueses para o desempenho das atividades comerciais. Pretendia-se oferecer à juventude, especialmente àquela que se encontrava ligada ao comércio por laços familiares, como sugere Áurea Adão,

uma preparação adequada em práticas contabilísticas e mercantis e no ensino da Caligrafia, com caracter eminentemente prático. Era portanto uma escola profissional, com um curso de três anos e cujo programa incidia sobretudo nas matérias comerciais: operações de aritmética, quebrados, regra de três e outras, pesos, medidas e moedas, câmbios, seguros, fretes, comissões, obrigações, escrituração dos livros por grosso e por retalho. ${ }^{26}$

Cerca de dois anos depois da publicação da Lei de reforma das aulas de Latim, Grego e Retórica, foi criado em Lisboa, a 7 de Março de 1761, o Real Colégio dos Nobres, na linha de opiniões de recomendação de Martinho de Mendonça de Pina e Proença, de Verney e, sobretudo, de Ribeiro Sanches, que vê publicadas as suas Cartas sobre a Educação da Mocidade em 1760. Este Colégio destinava-se, assim, a albergar 100 jovens que ali estudariam desde o ensino elementar.

Segundo Joaquim Ferreira Gomes, a reforma pombalina dos Estudos foi realizada em duas fases distintas,

a primeira, limitada àquilo a que hoje chamamos ensino secundário - e que, na época era uma parte dos Estudos Menores, iniciou-se em 1759, com a expulsão dos Jesuítas, e prolongou-se até 1771; a segunda fase, que engloba o

\footnotetext{
${ }^{25}$ A 6 de Novembro de 1772, D. José I, aprovou uma reforma geral do ensino elementar, introduzindo igualmente para o ensino médio, as aulas de Filosofia, que vinham sendo requeridas pelo Director-Geral dos Estudos.
}

${ }^{26}$ ADÃO, op. cit., p. 43-44. 
ensino primário, o ensino secundário (estudos menores) e a Universidade de Coimbra, começou a ser preparada antes de 1770 e teve a sua concretização a partir de $1772 .{ }^{27}$

A segunda fase da centralização de todos os Estudos teve lugar a partir de 1771, com a Real Mesa Censória. A criação desta Mesa, pela Lei de 5 de Abril de 1768, integra uma política cultural que, por sua vez, vai ao encontro da orientação geral do Governo. As competências da Real Mesa resultam da agregação das competências atribuídas antes ao Ordinário Diocesano, à Inquisição e ao Desembargo do Paço.

A sua fundação é um dado essencial no respeitante à política pombalina para os Estudos Menores. Se a princípio aquela instituição tinha a finalidade de reformar o sistema de censura, passou depois a superintender sobre todos os aspectos diretamente relacionados com o sistema de ensino, o que foi estabelecido por Alvará de 4 de Junho de 1771, numa política visivelmente centralizadora.

A Real Mesa Censória teve grande importância na implementação do ensino público, elaborando um Plano de cálculo, geral e particular, de todas e cada uma das Comarcas, e do seu número de habitantes, que poderiam beneficiar das Escolas Menores. ${ }^{28}$ Com base neste plano, foi elaborada a Lei de 6 de Novembro de $1772,{ }^{29}$ através da qual o Governo pombalino criou uma rede de escolas régias, de frequência gratuita, que abrangia todo o Reino, mais ampla do que a existente até então. Esta rede ficou inscrita no Mapa de professores e mestres das escolas menores e das terras em que se acham estabelecidas as suas aulas e escolas neste Reino de Portugal e seus domínios, anexo à Lei. E foi complementado pelo Suplemento ao Mapa dos Professores e Mestres das Escolas Menores, publicado juntamente com o Alvará datado de 11 de Novembro de 1773. Esta reforma geral de todos os Estudos Menores, aprovada pelo Rei pela Lei de 6 de Novembro, incluía também para o ensino médio as aulas de Filosofia, que vinham sendo requeridas pelo Director Geral dos Estudos.

A 10 de Novembro de 1772, uma Carta de Lei complementada por dois Alvarás com a mesma data, institui o imposto do Subsídio Literário. ${ }^{30} \mathrm{Um}$

\footnotetext{
${ }^{27}$ GOMES, Joaquim Ferreira. Luís António Verney e as Reformas Pombalinas do Ensino. In: Para a História da Educação em Portugal. Seis Estudos. Porto: Porto Editora, 1995, p. 74.

${ }^{28}$ Lei de 12 de Novembro de 1772 "hum Plano, e Cálculo Geral, e Particular de todas, e cada huma das Comarcas dos Meus Reinos e Domínios, e do número dos Habitantes dellas, que por hum regular, e prudente arbítrio podem gozar do benefício das Escolas Menores".

${ }^{29}$ A Lei de 6 de Novembro de 1772, "não extinguiu o ensino que vinha sendo ministrado pelas ordens religiosas, mas estas viram-se ultrapassadas nos privilégios e quase exclusividade que tinham tido".

${ }^{30} \mathrm{O}$ subsídio literário foi instituído para custear as despesas do ensino estatal. Era um imposto que recaía sobre a comercialização de produtos agrícolas, em especial sobre o vinho e a aguardente.
} 
dos Alvarás regulamenta a recolha do subsídio no Norte do País, enquanto o outro instituía a Junta encarregada de proceder à arrecadação do dito subsídio. Este imposto destinava-se especificamente a manter, em serviço público, um determinado número de professores e ao mesmo tempo assegurava o funcionamento das estruturas indispensáveis à implementação e funcionamento das escolas.

A política de estatalização do Ensino de Primeiras Letras e Estudos Menores, que marcou a formação da rede escolar pombalina, tal como sublinha Justino Magalhães, foi

contrariada, em parte, pela acção de alguns prelados que, à frente das suas dioceses procuraram oferecer uma alternativa educacional e escolar a públicos (...) com reduzido poder económico, alfabetizando-os e habilitandoos como técnicos e profissionais para as diversas actividades de escrituração (...) nos planos local e regional. ${ }^{31}$

Além disto, o plano do Marquês de Pombal não se esgotava na legislação já publicada para os Estudos Menores. A reforma do ensino superior preenchia também o seu pensamento e estava já a ser preparada há algum tempo. 0 trabalho preparatório da reforma da Universidade de Coimbra foi incumbido em 23 de Dezembro de 1770 à Junta de Providência Literária, criada para avaliar o estado do ensino português e preparar os novos estatutos, que iriam definir um novo planeamento reformista. A 28 de Agosto de 1772 foram finalmente publicados os Estatutos da Universidade de Coimbra, a ser aplicados nas seis Faculdades que a integravam: Teologia, Cânones, Leis, Medicina, Matemática e Filosofia.

Com a morte de D. José I, e a subida ao trono de D. Maria I, no ano de 1777, terminou o Governo político do Marquês de Pombal. Durante o seu reinado, apoiada pelo Clero e pela Nobreza, D. Maria I introduziu alterações na política da instrução pública sem destruir o fundamental que provinha das reformas pombalinas aplicadas no reinado do seu pai. Desta forma, manteve em serviço os mesmos estabelecimentos de ensino, a par de outros que religiosos e particulares iam abrindo.

Vinte anos após as reformas pombalinas, teve início uma nova reforma dos Estudos Menores, decretada por Lei de 16 de Agosto de 1779. Nos termos desta Lei, vários estabelecimentos de ensino público voltaram a ser confiados a religiosos. Por Alvará de 23 de Agosto de 1781, foi criada ainda a Aula Pública de Desenho.

Em 31 de Maio de 1790, a Rainha tomou a decisão de criar, em Lisboa, 18 lugares de mestras para meninas, proveniente da consulta de 25 de

\footnotetext{
${ }^{31}$ MAGALHÃES, Justino. Da Cadeira ao Banco. Escola e Modernização (séculos XVIII-XIX). Lisboa: Educa, 2010, p. 317.
} 
Fevereiro de 1790, feita pela Real Mesa da Comissão Geral sobre o Exame e a Censura dos Livros, onde é referida a importância de se criarem, na Corte, Mestras para a educação das meninas, no mesmo número que os Mestres públicos para meninos:

Parece à Mesa que a sobredita representação está nos termos de merecer a Real atenção de Vossa Magestade, mandando crear dezoito Mestras nesta Corte distribuídas pelos bairros para ensinarem gratuitamente as meninas na forma que fica expedido vencendo cada uma delas sessenta mil reis (...) sendo obrigadas a não admitir meninos ao ensino e ficando sujeitas a esta Mesa da mesma sorte que os demais professores (...). ${ }^{32}$

Esta resolução refere ainda, que as meninas deveriam ter Mestras diferentes: umas para ensinar a coser e a fiar, outras a bordar e a cortar, e outras a ler e a escrever, no entanto, todas elas tinham a obrigação de ensinar a doutrina cristã. Este mesmo documento sublinha a atribuição de 220.000 réis a um Sacerdote, que havia fundado, e que promovia, no sítio da Junqueira, a educação de meninas. ${ }^{33}$

O reinado de D. Maria I ficou ainda marcado pela publicação da Carta de Lei de 21 de Junho de 1787, pela qual a Real Mesa Censória foi substituída pela Real Mesa da Comissão Geral sobre o Exame e a Censura dos Livros. Esta veio a ser substituída pela Junta da Diretoria-Geral dos Estudos e Escolas do Reino, criada em 17 de Dezembro de 1794, ficando em funções até 1820.

\section{O Projeto Atlas - Repertório dos Municípios na Educação e na Cultura em Portugal: $1^{\circ}$ quadro do projecto $(1770-1801)^{34}$}

\section{Análise de dados dos Estudos Menores}

Através de um estudo documental sobre este período (reinado de D. José I e D. Maria I) e da consulta das fontes compulsadas e recolha de dados, no âmbito do Projecto Atlas-Reportório dos Municípios na Educação e na Cultura em Portugal (1820-1986), foi possível reconstituir-se a rede escolar existente em Portugal no período compreendido entre 1770 e 1801.

\footnotetext{
${ }^{32}$ A.N.T.T., Ministério do Reino, Junta da Directoria Geral dos Estudos, Cx. 692, maço 592, (1790-1815).

${ }^{33}$ Apesar de alguns autores referirem que as 18 cadeiras de instrução primária para o sexo feminino, criadas nesta data, só entraram em funcionamento pela resolução régia de 13 de Fevereiro de 1815, apurou-se, através dos livros de vencimento dos professores do Arquivo do Tribunal de Contas, a existência de 4 mestras, em 1795. Cf. Teresa Rosa e Patrícia Gomes. Os Estudos Menores e as Reformas Pombalinas. Revista Interacções, 2014, p. 49-50.

${ }^{34}$ Texto produzido no âmbito do Projecto Atlas-Repertório dos Municípios na Educação e na Cultura em Portugal (1820-1986), financiado pela FCT (Refa. PTDC/CPE-CED/116938/2010).
} 
As fontes utilizadas nesta análise foram, principalmente, as folhas de vencimento dos Mestres e Professores régios que se encontram atualmente no Fundo Documental do Erário Régio, no Arquivo Histórico do Tribunal de Contas, ${ }^{35}$ para as cadeiras de ler, escrever e contar referentes ao ano de 1794 e para as cadeiras de gramática latina, língua grega, retórica, filosofia e desenho, foi tomado para referência o ano de $1795 .{ }^{36} \mathrm{~A}$ existência dos vários estabelecimentos de ensino recolhidos para estes dois anos foi confirmada pelos dados constantes na consulta feita, nos anos de 1800, pela Junta da Diretoria-Geral dos Estudos e Escolas do Reino. Estes dados permitiram-nos ainda acrescentar uma rede de ensino de iniciativa particular bem como das ordens religiosas.

No que respeita ao ensino nas ilhas da Madeira e dos Açores, as fontes anteriormente citadas são omissas. Desta forma, foi tida como fonte principal o Mapa dos Professores e Mestres das Escolas Menores e das terras em que se acham estabelecidas as suas aulas e escolas neste Reino de Portugal e seus domínios, anexo à Lei de 6 de Novembro de 1772, foi complementado pelo Suplemento ao Mapa dos Professores e Mestres das Escolas Menores, publicado juntamente com o Alvará datado de 11 de Novembro de 1773. A recolha de informação referente às ilhas foi também apoiada nos dados publicados na obra História dos Municípios e do Poder Local, ${ }^{37}$ e no trabalho de Rogério Fernandes, Educação e Ensino Popular na Madeira (séc. XVIII-1840). ${ }^{38}$

Figura 1 - Número de Estabelecimentos de Ensino por Disciplina

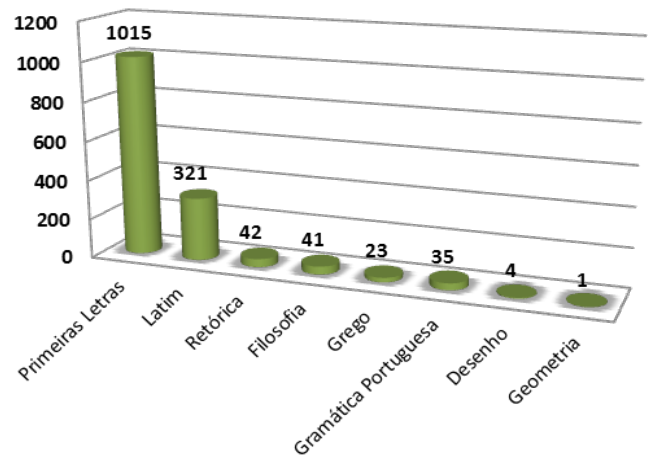

\footnotetext{
${ }^{35}$ A.T.C. Erário Régio: Livros 3897 a 3903.

${ }^{36} \mathrm{Cada}$ ano económico é constituído por um livro principal e diversos suplementos que complementam a informação contida no primeiro. In: ROSA e GOMES, op. cit., p.48.

${ }^{37}$ MONTEIRO, Nuno. Os Poderes Locais no Antigo Regime. In: História dos Municípios e do Poder Local. Lisboa: Circulo dos Leitores, 1996, p. 79-119.

${ }^{38}$ FERNANDES, Rogério. Educação e Ensino Popular na Madeira (séc. XVIII-1840). Separata da Revista da Universidade de Coimbra, XXVIII, 1992, p. 1-69.
} 
Tendo por base as fontes referidas, para este primeiro quadro, foi possível identificar que na sua grande maioria os estabelecimentos de ensino são escolas de Primeiras Letras (1050), seguidas por 321 escolas onde era ensinado o Latim (sendo que nove delas também lecionavam a Gramática Portuguesa), seguindo-se 42 escolas de Retórica, um número muito próximo de escolas de Filosofia, 41 e 35 de Gramática Portuguesa. As escolas de Grego são por sua vez, 23, as de Desenho 4 e, por último, a de Geometria apenas 1.

Figura 2 - Evolução dos Estudos Menores em Portugal Continental entre os anos 1773 e 1795

\begin{tabular}{|c|c|c|}
\hline Ano & Escolas de ler, escrever e contar & $\begin{array}{c}\text { Cadeiras de estudos menores } \\
\text { (latim, grego, retórica, filosofia e } \\
\text { desenho) }\end{array}$ \\
\hline $1773^{39}$ & 486 & 341 \\
\hline $1778^{40}$ & 726 & 292 \\
\hline 1794 e 1795 & $760^{41}$ & $174^{42}$ \\
\hline
\end{tabular}

Rosa, Teresa \& Gomes, Patrícia. Os Estudos Menores e as Reformas Pombalinas. In: Revista Interacções, Vol. 10 , № 28, 2014.

À consulta das fontes atrás descrita, com o objetivo de visualizar a evolução dos Estudos Menores em Portugal Continental, desde a sua criação, em 1772, até ao final do século XVIII, e tomando como referência o Mapa dos professores e mestres das escolas menores e das terras em que se acham estabelecidas as suas aulas e escolas neste reino (...) anexo à lei de (6/11/1772), e complementado pelo Suplemento ao Mapa de Professores e Mestres de Escolas Menores, publicado com o Alvará de (11/11/1773), estava previsto o estabelecimento de 827 aulas públicas em Portugal Continental, sendo 341 Professores das cadeiras de (latim, grego, retórica, filosofia e desenho), e 486 escolas de ler, escrever e contar.

Acrescentando a estas fontes a Lista das terras, conventos e pessoas destinadas para professores de filosofia racional, retórica, língua grega, gramática latina, desenho, mestres de ler, escrever e contar (...) por resolução real de S. Majestade de 16 de Agosto (...) de 1779, tomada em consulta da Real Mesa Censória de

\footnotetext{
${ }^{39}$ Para a Comarca de Coimbra foram contabilizadas as cadeiras existentes em 1773.

${ }^{40}$ Biblioteca Nacional de Portugal, Res. PBA 462.

${ }^{41}$ Número correspondente ao ano de 1794.

${ }^{42}$ Número correspondente ao ano de 1795, sem as escolas da Comarca de Coimbra, que se encontram registadas no ano de 1773 .
} 
12 de Janeiro de 1778, nesse ano deveriam existir no território de Portugal Continental 1018 estabelecimentos de ensino, com 292 cadeiras de Estudos Menores onde são compreendidas as disciplinas de (filosofia racional, retórica, língua grega, gramática latina e desenho) e de 726 de ler, escrever e contar.

Pela recolha feita, para os anos de 1794/95, nos Livros de Pagamento aos Mestres e Professores do Fundo do Erário Régio, foi possível contabilizar 934 aulas públicas. Sendo que as cadeiras dos Estudos Menores (latim, grego, filosofia, retórica e desenho), eram 174 cadeiras e 760 de ler, escrever e contar. Nesta leitura importa ainda ter em conta que para a Comarca de Coimbra apenas se incluem as cadeiras em 1773.

Figura 3 - Número de Alunos Matriculados nas cadeiras de Estudos Menores no ano de $1775^{43}$

\begin{tabular}{|c|c|c|}
\hline Disciplinas & Total/alunos & $\begin{array}{c}\text { Localidades com maior } \\
\text { número de alunos }\end{array}$ \\
\hline Gramática Latina & 2289 alunos & Braga, Porto, Vila Real, Faro e Beja \\
Retórica & 357 alunos & Braga, Porto, Viana e Lisboa \\
Filosofia Racional & 310 alunos & Porto, Vila Real, Viana e Lisboa \\
Língua Grega & 126 alunos & Lisboa e Porto \\
\hline
\end{tabular}

Através de uma lista de alunos matriculados nas cadeiras de Estudos Menores, enviada à Real Mesa Censória no ano de 1775 pelos Professores, podemos registar a matrícula de 2289 alunos na gramática latina, seguindo-se a retórica com 357, a filosofia racional com 310 e a língua grega com 126 alunos. Podemos ainda verificar que nesta lista se encontra em falta o registo do número de alunos de algumas localidades, informação possivelmente enviada à Real Mesa numa data posterior.

Por outro lado, a documentação resultante da consulta de 1800, já referida anteriormente, permitiu-nos confirmar, não só a existência de Escolas pagas pelo Estado, como também Professores que, a título particular, ensinavam a ler a escrever e contar num total de $210 . .^{44}$ Enquanto que os Professores particulares de gramática latina, filosofia, língua grega e retórica perfaziam um total de 64. Trata-se de uma rede particular que complementa

\footnotetext{
${ }^{43}$ B.P.A.D.E., cód. CXXVIII/2-20, №s. 106, 107, 108 e 109.

${ }^{44}$ Apud ROSA e GOMES, op. cit., p. 52.
} 
a oferta do Estado, à qual poderemos ainda acrescentar as disciplinas de Estudos Menores leccionadas pelas Ordens Religiosas. $O$ que nos permite concluir que a Escola pública existente era manifestamente insuficiente para o número de jovens em idade escolar, e que, para o período correspondente ao reinado de D. Maria I, houve um aumento significativo de cadeiras de Estudos Menores entregues com maior frequência às Ordens Religiosas ${ }^{45}$ tal como sugere Rogério Fernandes,

Um dos traços essenciais da política de ensino elementar, (...) é o alargamento da rede de cadeiras de Primeiras Letras (...). Tal acréscimo, porém, far-se-ia à custa do recurso às ordens religiosas como agentes de difusão do ensino. (...) As primeiras disposições tomadas por D. Maria I nesta matéria acham-se consubstanciadas em mais de um documento, o primeiro dos quais se intitula Lista de terras, conventos, e pessoas destinadas para professores de Philosophia Racional, Rhetorica, Lingua Grega, Grammatica Latina, Desenho, Mestres de Ler, Escrever e Contar (...) tomada em consulta da Real Meza Censória de 12 de Janeiro de 1778. (...) Outro documento, complementar deste, tem a data de 10 de Setembro do ano de 1779. (...) Os anos de 1778-1779 marcaram o início da política de entrega dos Estudos Menores às congregações religiosas como os documentos referenciados confirmam (...). ${ }^{46}$

Podemos destacar ainda que o número de Mestres de ler, escrever e contar, foi aumentando progressivamente ao longo do tempo, enquanto as restantes cadeiras de Estudos Menores (filosofia, retórica, língua grega, gramática latina e desenho) verificaram o fenómeno inverso.

Tendo por base a documentação mencionada e a recolha de dados analisada referente ao Erário Régio e Junta da Diretoria-Geral dos Estudos e Escolas do Reino, podemos observar ainda, através da leitura dos seguintes gráficos, a distribuição das cadeiras de Estudos Menores lecionadas pelas Ordens Religiosas entre os anos de 1794 e $1800^{47}$, bem como as Ordens com maior incidência nessa lecionação, assim como a distribuição dessas cadeiras pelas Comarcas de maior significado nesse ensino.

45 Cf. gráficos.

46 FERNANDES, Rogério, Os Caminhos do ABC - Sociedade Portuguesa e Ensino das Primeiras Letras. Porto: Porto Editora, 1994, p. 78.

47 Além da rede Escolar do Estado e das disciplinas entregues a Mestres e Professores particulares. 
Figura 4 - Disciplinas leccionadas pelas Ordens Religiosas entre 1794 e 1800

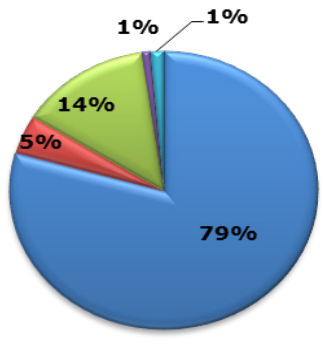

arimeiras Letras

Filosofia

Q Latim

Gramática

Portuguesa

Retórica

Figura 5 - Ensino das Primeiras Letras distribuído pelas Ordens Religiosas entre 1794 e 1800

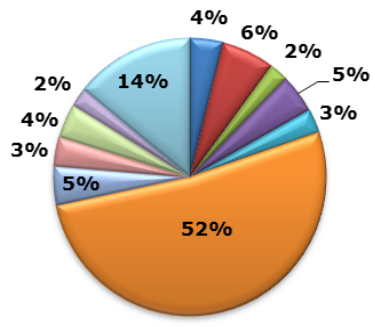

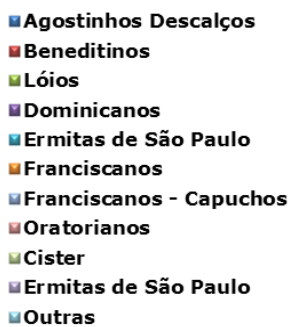

Figura 6 - Ensino da Filosofia distribuído pelas Ordens Religiosas entre 1794 e 1800
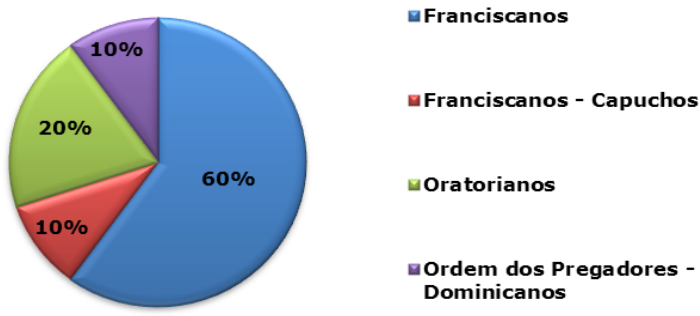

Figura 7 - Ensino do Latim distribuído pelas Ordens Religiosas entre 1794 e 1800

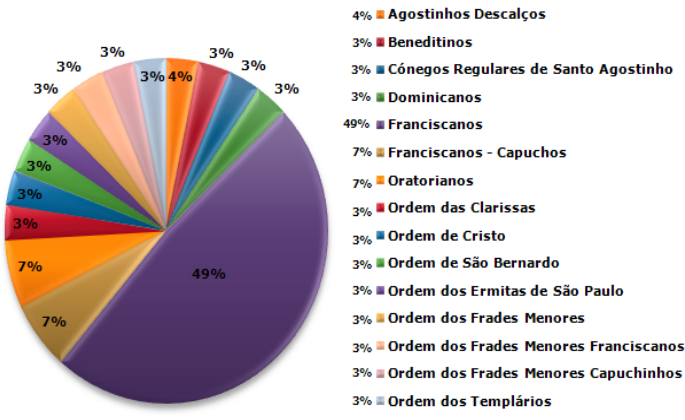


Figura 8 - Distribuição do ensino das Primeiras Letras pelas Ordens Religiosas / por Comarca entre 1794 e 1800

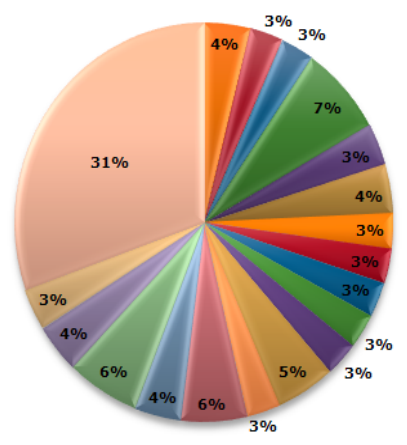

$$
\begin{aligned}
& 4 \% \text { Algarve } \\
& 3 \% \text { aveiro } \\
& 3 \% \text { marcelos } \\
& 7 \% \text { ш } \text { Beja } \\
& 3 \% \text { a Castelo Branco } \\
& 4 \% \text { Elvas } \\
& 3 \% \text { = Guarda } \\
& 3 \% \text { Guimarães } \\
& 3 \% \text { Lisboa } \\
& 3 \% \text { w Ourique } \\
& 3 \% \text { a Penafiel } \\
& 5 \% \text { a Portalegre } \\
& 3 \% \text { Santarém } \\
& 6 \% \text { asetúbal } \\
& 4 \% \text { ш Torre de Moncorvo } \\
& 6 \% \text { च Viana do Castelo } \\
& 4 \% \text { avila Viçosa } \\
& 3 \% \text { Viseu } \\
& 31 \%=\text { Outras }
\end{aligned}
$$

Figura 9 - Distribuição do ensino de Filosofia pelas Ordens Religiosas / por Comarca entre 1794 e 1800

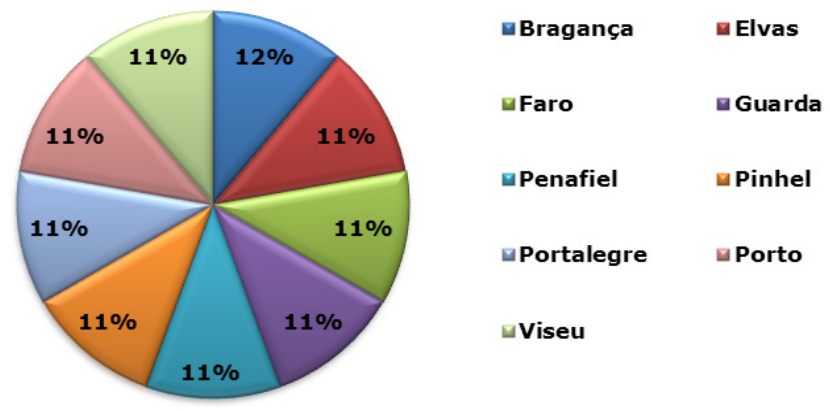

Figura 10 - Distribuição do ensino do Latim pelas Ordens Religiosas / por Comarca entre 1794 e 1800
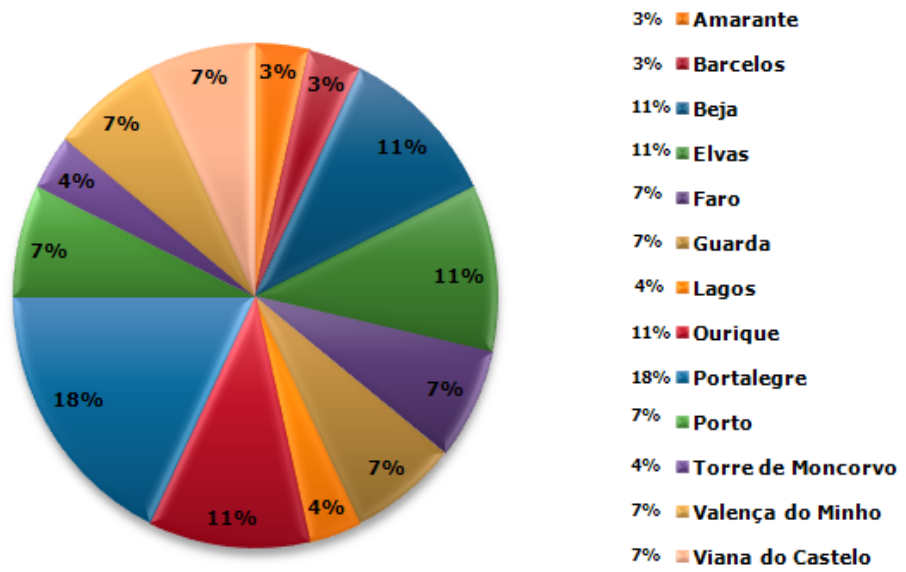
Da leitura efetuada através da análise dos dados, podemos depreender o seguinte: das disciplinas lecionadas pelas Ordens Religiosas, 79 \% representam o ensino nas Escolas de Primeiras Letras, seguindo-se o ensino do Latim com cerca de $14 \%$ e da Filosofia com 5\%. Das 34 Ordens Religiosas que lecionavam as Primeiras Letras num total de 177 Escolas, destaca-se a Ordem de São Francisco com um peso de 52\% desse ensino, com cerca de 92 Escolas, os Beneditinos, com 11 Escolas, e cerca de 6\%, os Dominicanos e os Capuchos com $5 \%$. Sendo ainda que $14 \%$, representam outras Ordens cuja representatividade seria apenas de 1 a 3 Escolas por Ordem Religiosa.

Quanto ao ensino de Filosofia, encontramos de novo a Ordem de São Francisco com a maior percentagem de lecionação 60\%, seguindo-se a Congregação do Oratório com 20\%, e as Ordens dos Capuchos e Dominicanos com $10 \%$ cada. Em relação ao Latim, a Ordem de São Francisco torna a destacar-se com cerca de 49\%, seguindo-se com uma diferença assinalável a Ordem dos Capuchos com 7\% e a Ordem de Santo Agostinho com 4\%, todas as outras com uma percentagem inferior.

Por outro lado, foi considerado um universo de 40 Comarcas com mais de (cinco escolas de primeiras letras), sendo que 31\% (outras) possuíam menos de 5 escolas. Assim sendo, na leitura do gráfico depreendemos que Beja seria a Comarca com mais escolas de primeiras letras com cerca de 7\%, equivalente a 13 escolas, seguida de Viana do Castelo com 11 escolas, cerca de 6\%.

Em relação ao ensino do Latim encontramos um maior peso na Comarca de Portalegre com 18\%, cerca de 5 Escolas, e de Ourique com 3 Escolas, cerca de $11 \%$. E no ensino de Filosofia uma média de 11\% a 12\% nas Comarcas de Bragança, Elvas, Faro, Guarda, Penafiel, Pinhel, Portalegre, Porto e Viseu, com uma Escola apenas.

Deste estudo podemos concluir que durante o Governo pombalino foi criada uma rede de escolas régias de frequência gratuita, que abrangia todo o Reino, mais ampla do que a existente até então. Esta reforma geral de todos os Estudos Menores, aprovada por D. José I, através da Lei de 6 de Novembro de 1772, incluía também para o ensino médio as aulas de Filosofia que vinham sendo requeridas pelo Diretor Geral dos Estudos. Esta Lei, não extinguiu o ensino que vinha sendo ministrado pelas ordens religiosas, mas estas viram-se ultrapassadas nos privilégios e quase exclusividade que tinham tido.

Para o período correspondente ao reinado de D. Maria I, ouve um aumento significativo de cadeiras de Estudos Menores entregues com maior frequência às ordens religiosas. Os anos de 1778-1779, marcaram o início da 
política de entrega dos Estudos Menores às congregações religiosas. O número de Mestres de ler, escrever e contar foi aumentando progressivamente ao longo do tempo, enquanto as restantes cadeiras de Estudos Menores (filosofia, retórica, língua grega, gramática latina e desenho) verificou o fenómeno inverso. Podemos evidenciar ainda, a importância da Ordem de São Francisco, na lecionação dos Estudos Menores durante o reinado de D. Maria I.

Artigo recebido para publicação em 28/10/2014 Artigo aprovado para publicação em 25/11/2014 